\title{
Organization's Human Resource Practices: Determinants of Employees Retirement Preparedness in the Context of Kenya
}

\author{
Githaiga Gathiira ${ }^{1}$, , Stephen Muathe ${ }^{2}$, James Kilika ${ }^{2}$ \\ ${ }^{1}$ Department of Planning and Administration, Karatina University, Karatina, Kenya \\ ${ }^{2}$ Department of Business Administration, Kenyatta University, Nairobi, Kenya
}

Email address:

ggathiira@gmail.com (G. Gathiira),muathesm@yahoo.com (S. Muathe),jmkilika@gmail.com (J. Kilika)

${ }^{*}$ Corresponding author

\section{To cite this article:}

Githaiga Gathiira, Stephen Muathe, James Kilika. Organization's Human Resource Practices: Determinants of Employees Retirement Preparedness in the Context of Kenya. Journal of Human Resource Management. Vol. 8, No. 3, 2020, pp. 152-162. doi: $10.11648 /$ j.jhrm.201200803.16

Received: June 5, 2020; Accepted: July 1, 2020; Published: July 6, 2020

\begin{abstract}
The premise that human resource (the people) is the most valuable of all organizational resources presupposes the need for organizational strategies to secure the future of both the organization and employees. The role played by employer organizations in employee separation planning is imperative in providing insight into the human resource practices geared towards employees' eventual retirement. However, separation decisions are ignored in theory and practice, and even the little attempts made has inherent weaknesses. This has left employees' retirement planning being a concern of individuals just about to retire or otherwise plunging into retirement life without planning at all. Separation planning predicts higher levels of individual's postretirement adjustment across various occupational settings in both public and private sectors. There is therefore need for judicious management of retirement transition by individual employees and employers through promotion of sound human resource practices. The human resource practices should intentionally influence individual employee's retirement behaviours by triggering planning for the eventual separation and hence retirement preparedness. The purpose of this study was to assess the effect of organization's human resource practices and retirement preparedness among public secondary school teachers' in Kenya. The target population was 1,238 teachers aged 50 years and above, employed in public secondary schools by the Teachers Service Commission in Kirinyaga and Murang'a Counties by 2017. A representative sample of 334 respondents was selected using multistage sampling technique. Data was collected using semi structured questionnaire and interview guide. Logit regression was used to establish the relationships between variables in the study and to test hypotheses at $\mathrm{P} \leq 0.05$ at $95 \%$ confidence level. The study found that human resource practices influence retirement preparedness positively. The study therefore concluded that sound HR practices should be put in place by the employer organizations to offer conducive environment that make employee separation planning and retirement preparedness possible. The study recommended the government through its agencies and/or Commissions to enact frameworks that enforce, monitor and evaluate diversified human resource practices for employer organizations to establish policies and guidelines that facilitate employees' engagement in programmes that ensure a continuous process of separation planning for successful retirement preparedness.
\end{abstract}

Keywords: Employee Separation Planning, Organization Human Resource Practices, Retirement Preparedness, Retirement Planning, Separation Planning, Human Resource Practices, Teachers

\section{Introduction}

Retirement Preparedness (ReP) for Employee's Separation Planning (ESP) ought to start a long while before individuals exit the workforce [1]. Employees should contemplate ReP and commence Retirement Planning as soon as they enter the employment [2]. The argument is based on the observation that, retirees wellbeing to a large extent mirror the 
individual's level of ReP during employment life [3]. It is therefore a matter of great concern that retirement life of many individuals is normally accompanied by deterioration of life satisfaction [4]. Human Resource Management (HRM) ought to depict the value of retirement planning in order to foster a symbiotic relationship between organizations and their employees by the former achieving business goals, and likewise promote Human Resource Practices (HRPs) that influence ESP decisions [5]. Studies have found existence of several dynamic strategies that individual employees can engage in to re-invent themselves during retirement [6]. As part of employees training and development therefore, ReP for ESP should be an agenda of policy makers and scholars that study HRPs in HRM [7]. Retirement preparedness portrays a rational decision that employees must antagonize with through advertent choices and behaviour geared towards precise retirement outcomes [8]. Unfortunately, employees fail to make comprehensive plans about when to retire and what to do in retirement [9]. This is probably due to lack of an empowering work environment. Conducive work environment in form of sound HRPs is imperative in offering rich impetuses for ReP [10]. To ensure more options in retirement, employees require to increasingly give serious thought to the form of retirement that best suit their circumstances by engaging into a deliberate separation planning [11].

Studies have found new population trends that include increased life expectancy, health status and increased education level in population [12]. Consequently, people aged above 60 years are expected to triple in the next 45 years, a phenomenon that is similar in both developed and developing countries [13]. For instance, $30 \%$ of the teaching profession in France is over 50 years against mandatory retirement age (MRA) of 60, an indication of large number of pre-retiree teachers. In Germany, 70\% are expected to retire within the next 15 years while England has more than $60 \%$ of school leaders anticipated to retire during the next decade [2, 7]. The situation is similar in Kenya where the Teachers Service Commission (TSC) recruits new teachers annually to replace teachers who have left the commission through what is referred to natural attrition. Ageing population is not the problem in itself [2] but the extent of preparedness by preretirees, since ReP is a function of HRPs in place to support retirement planning, bearing in mind retirement life may last over 20 years [14]. There is therefore dire need to incorporate employer organizations as key players in promoting ReP of employees by developing and implementing HRPs that empower pre-retirees [7]. The problem of the study therefore is that, despite the much research conducted on retirement mostly in western countries and in other sectors of the economy, the effect of HRPs on ReP and especially so in the education sector remain to a large extent explained $[15,16]$. The authors sought to address this gap by availing empirical data on the effect of Organization HRPs on secondary school pre-retiree teachers' retirement preparedness.

The purpose of this study was to assess how organizations HRPs affect ReP of pre-retirees among public secondary school teachers in Kenya. The specific objectives of the study were to assess the effect of Flexible Work Arrangements (FWA), Formation of Alumni Networks (FAN), Employee Disengagement Process (EDP) and Career Development (CD) on retirement preparedness among public secondary school teachers in Kirinyaga and Murang'a Counties in Kenya. The study contributes in filling the knowledge gap concerning the interconnection between organizations HRPs and retirement preparedness in ESP, a construct in HRM that has been ignored in theory and practice [2] despite the recognition that management of employee separation by employer is a daunting assignments [17].

\section{Literature}

\subsection{Theoretical Review}

From the existing state of theoretical and conceptual literature on ESP arising from individuals reaching MRA, it makes ReP a significant function in HRM. The concept has affected the wellbeing of retirees and therefore becomes significant to address this phenomenon by anchoring employee separation in suitable theoretical foundations. The study was anchored in three theories that promoted comprehension of HRPs and their nexus with ReP of preretiree teachers. The theories were continuity theory (CT), life course perspective (LCP) and the theory of planned behaviour (TPB). CT envisages retirees' life without significant drop in well-being because individuals adapt to the changing environmental conditions by holding on to habits and activities that were fundamental to them before retiring [18]. Employees are therefore expected to make decisions that ensure continuity of postretirement work activities and social life perceived valuable to them prior separation [19]. It is therefore anticipated that pre-retirees planned activities consistent with the current life activities will exhibit ReP. Unlike the assumption of CT that predicts a continuous advancement in activities without disruptions, LCP recognizes that people may make multiple entries and exits in work during their lifetime since retirement is a process and not an event [16]. Therefore, LCP underscores that life changes are contextually entrenched, suggesting that experiences of individual's retirement adjustment are contingent on the definite circumstances under which they occur [20]. The TPB central factor is the individual's intentions that capture the motivational fundamentals that influence performance of a given behaviour [21]. TPB envisages deliberate behaviour intent of individual's selfefficacy beliefs that influence the choice and preparation for an activity, effort expended during performance, thought patterns and emotional reactions put in the activity [22]. Therefore, TPB recognizes behavioural control and intention utilization to predict behavioural achievement with considerable accuracy especially when behaviours do not pose severe problems of control [23]. Due to the aforementioned reasons, the authors conceptualized organizations to have developed and implemented HRPs that 
motivate employees behaviours inclined to certain activities that safeguard wellbeing in post-retirement life. Hence, the three theories - CT, LCP and TPB anchored the study in assessing the effect of organizations HRPs on retirement preparedness.

\subsection{Conceptual Empirical Review}

In providing better understanding to pre-retiree's career decisions, incorporating employer organizations as key players in $\mathrm{ReP}$ for pre-retirees through developing and implementing HRPs, policies, actions and attitudes is inevitable [7]. It is incumbent therefore, to delineate the role employer organizations play in employment and retirement nexus in order to understand the HRPs geared towards employees (the people) - the most valuable of all organizational resources [16]. This presupposes the need for organizational strategies to secure the future of both the organization and employees. In developing HRPs that would favour pre-retirees, it was found that employer organizations have limited options to circumvent government policies [24]. As noted by Barnett, et al. (2012), almost half of the United State of America (USA) organizations had employed retirees in the early 1990s but very few had established formal policies on the employment of retirees [10]. In taking this argument further, Ozgen, et al. (2020) postulates that employer organizations should consider application of HRPs that support retirement transition adjustment in order to adapt to the changing environment of retirement planning [25]. The rational is that, employer organizations are central in providing choices and opportunities for employees. Past studies have given little consideration to determining the critical role that employer organizations play in $\mathrm{ReP}$ [24]. It therefore remains uncertain how HRPs embraced by employer organizations shape ReP of pre-retirees. Noteworthy, most successful employer brands have HRPs aligned to business and corporate objectives with the professional, personal, and social goals of their employees [26]. Along similar lines, Benko, et al. (2014). uphold that HRPs would better shift to strategies that attract and engage employees through measures that align individual goals and experience with corporate purpose [27].

In this study, HRPs were measured by FWAs, FAN, EDP and CD. HRPs that promote FWAs include work scheduling, flexible hours, voluntary work-time reductions, work parttime or in shifts, vacation and leave of absence for various reasons, flexible work locations, working at the office or at home, job-sharing, phased retirement, job assignment, improved workplace organization, hiring and contracting strategies, training practices and compensation methods [28, 29]. This FWAs avail more flexible working environments that inspire pre-retirees to adopt gradual retirement while the employer benefit by having opportunities to recruit and retain high performance employees in addition to stimulating employee's workplace engagement [30]. FWAs favour preretirees that repel traditional full-time schedules, due to additional personal obligations, worsening health, declining physical energy or preference in trading some income for more control over their time without giving up paid employment in entirety [31]. As advocated by Scholosser et al., (2011), the FWA is a good alternative to many older workers in doubt of complete severing from employer organization [32]. Consequently, transitional labour market that prefer partial transitions retirement as opposed to fulltime retirement are attractive to pre-retirees. FWA such as part-time work provides a symbiotic relationship that contributes to transfer of knowledge and experience to novice employees, besides assisting older employee to ease transition adjustment [7]. As urged by Wood, et al. (2010) countries that eliminated MRA have adapted flexible working environment to facilitate productive employment of older employees [33]. However, retirement arrangements and pathways are determined by organizational culture [12]. This is because, culture change is imperative in combating cultural biases and age-based stereotypes that pose obstacles in application of new retirement initiatives and practices [34]. The study assessed the effect FWAs on ReP.

Corporate alumni network is an organization's HRPs that stimulate retirement planning because, it assists managers to identify retirees who are willing to return to the organization in some paid capacity such as bridge employment [35]. As established by Quinn (2010), training new employees using older employees as resource persons in jobs similar to their previous ones provides a mutual beneficial relationship between the organization and the retirees [36]. This is a symbiotic relationship since such trainings pass on organizational intelligence and provide institutional memory to work groups. The FAN also form environmental connections to new retirees from the organization they worked thus building a network of corporate associates in post-retirement life [35]. Such networks form sources of reliable psychosocial support. The study therefore established the effect of FAN on ReP.

As argued by Wohrmann, et al. (2014), interventions at organizational level about retirement planning by HR managers might include provision of employees with information on positive outcomes about work engagements after separation [18]. Pre-retirees are usually affected by disengagement processes and psychological withdrawal from the work place years before the real separation as they mourn the fear of social exclusion in postretirement life [37]. Therefore, as a strategy for changeover adjustments, preretirees opt for hybrid type of employment that allow phased retirement; with very few deciding on traditional full leisure retirement [7]. This gradual employee disengagement from working life is a process of reducing attachment to work as pre-retirees map their next career development pathway [37]. The EDP should include sensitization of employees by employer about pension schemes [5]. As argued by Sargent et al. (2012), there is a decreasing trend of Direct Benefit (DB) to Direct Contribution (DC) pensions schemes [12]. In view of this, the authors contend that, retirement policies and practices should be part of the HRM system in organizations to smoothen EDP. The study investigated the effect of employee disengagement process on retirement preparedness. 
Pre-retirees are confronted with different work exit strategies such as prolonging work life through career or noncareer paths subject to opportunities available in their mid and late careers and the constraints existing in their operational environment [38]. With sound organization's HRPs that provide opportunities for career growth and development, pre-retirees should have amassed adequate skills and knowledge that act as competitive edge in postemployment life. Intrinsically, organization's role in ESP is essential in providing career growth through training and development via career guidance and information, mentorship, coaching and other advancement opportunities [39]. This type of career management shift is reinforced by other researchers who found that traditional career development equation has shifted to more flexible and dynamic approaches that define different roles for individuals and organizations in career management $[40,41]$. The new model depicts a changed relationship between employer's employees' expectations. This argument is supported by Neal (2015), who posit that both organizational and individual factors that promote pre-retirees' adjustment are influential in the retirement process [42]. The study therefore assessed the effect of career development practices on ReP. As supported by Jenkins (2013), organizations should put in place HRPs to provide individual guidance, support and encouragement needed to realize inherent potential and achieve successful career aligned to talents and aspirations [11]. The foregoing literature put forward a strong case that application of appropriate HRPs influence ReP thus delineating the role played by employers in late career employment - employee retirement nexus, hence the study.

\subsection{Conceptualization and Hypotheses}

The HRPs and ReP variables were modeled as presented in figure 1 .

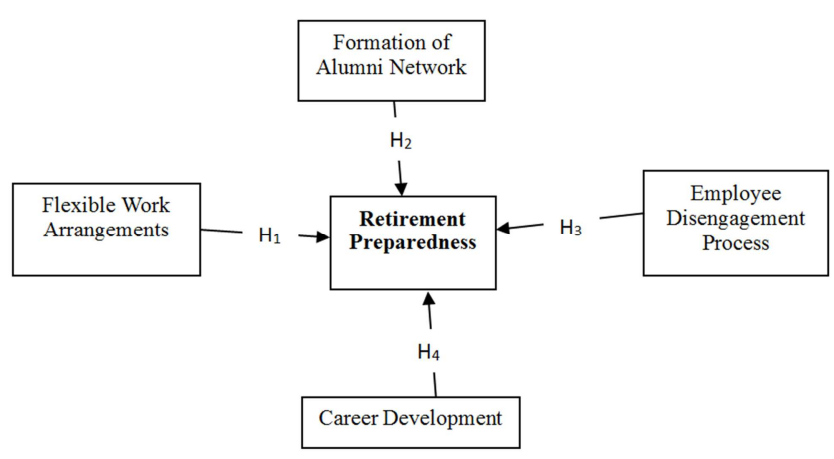

Figure 1. Conceptualization and Hypotheses.

From the deduction of empirical evidence from previous studies and theoretical literature [7, 33], the authors postulated a positive relationship between HRPs and ReP. There being no other studies with dissimilar findings, we proposed that HRPs will positively influence the degree of ReP. The study proposed the following hypotheses, that:

$\mathrm{H}_{1}$ : There is a significant effect of flexible work arrangements on retirement preparedness among public secondary school teachers in Kenya;

$\mathrm{H}_{2}$ : There is a significant effect of formation of alumni network on retirement preparedness among public secondary school teachers in Kenya;

$\mathrm{H}_{3}$ : There is a significant effect of employees' disengagement process on retirement preparedness among public secondary school teachers in Kenya; and

$\mathrm{H}_{4}$ : There is a significant effect of career development on retirement preparedness among public secondary school teachers in Kenya.

\section{Methodology}

\subsection{Context of Study}

The Kenyan education system comprise of basic education (primary and secondary), Tertiary education and university education [43]. Administration and management of education is devolved to the forty-seven Counties that are headed by the County Directors of Education while the head of secondary school (the principal) is mandated with day to day running of the schools supported by the Boards of Management. The study was conducted in Kirinyaga and Murang'a counties because the two had suffered more loss of life due to abuse of alcohol compared to other counties in Kenya [44] and the sufferers included teachers. Retirement poses significant adjustment challenges for older employees depending on the level of occupation embeddedness. Academic professionals tend to have strong work identity and hence find it difficult to retire since they feel life will become valueless or meaning without work [45]. Psychosocial disorder factors related to perceived lack of support upon retirement lead to negative effects that include lifestyle changes, stress, anger, hostility, depression, alcohol and substance abuse [46]. Bamberger (2014) posit that retirement is a significant life occurrence that influence older adults' drinking behavior, aggravating prior patterns of heavy drinking or even triggering alcohol abuse [47].

\subsection{Design, Target Population and Sampling}

This study used descriptive research design [48] because it provided a comprehensive and thorough explanation of the phenomena of pre-retiree teachers ReP in view of the HRPs in place for a conclusive research [49]. The target population was 1,238 TSC employed teachers in secondary schools of Kirinyaga and Murang'a Counties that were 50 years and above by 2017 . The study employed Yamane (1967) formula, to get a sample size $302(24.39 \%)$. However, the authors enlarged the sample size to $334(26.98 \%)$ in order to avoid Type I error (false rejection of a true $\mathrm{H}_{0}$ ) and Type II error (erroneous acceptance a false $\mathrm{H}_{0}$ ). As argued by Fox, et al (2009), hypotheses testing studies that seek to generalize findings require to enhance statistical significance and statistical power by increasing sample size to accommodate non-responses [50]. Multistage sampling technique (three stages) was adopted because the population was scattered over a wide area [51]. Identification of Kirinyaga and 
Murang'a counties from the 47 counties used convenience sampling due to their proximity to the researcher formed stage one. Stage two was identification of the school category - National, Extra County, County and Sub-County - using proportionate stratified sampling technique. Stage three involved selection of the actual respondents using purposeful sampling technique to identify TSC employed teachers aged 50 years and above.

\subsection{Research Data}

Semi-structured questionnaires were used to collected data. Section I had seven items on respondents' demographic profile. HRPs as composite variable had four explanatory variables with items captured in four sections. Section II had nine items on FWA, section III had five items on FAN, section three had 19 items on EDP and section four had four items on $\mathrm{CD}$. The items for the independent variable were measured in 5 - point Likert Scale as follows; Not at all (1), Slight extent (2), Moderate extent (3), High extent (4) and very High extent (5). ReP was also measured in 5 - point Likert Scale - definitely false (1), false (2), neither (3), true (4) and definitely true (5).

\subsection{Diagnostic Tests}

Collinearity tests were conducted using correlation analysis, tolerance and Variance Inflation Factor (VIF) analysis. Tolerance statistics was to be above 0.1 and VIF less than 10 for no concern of multicollinearity problem [52]. Since VIF values was 1.244 and tolerance statistics 0.804 , the study concluded that multicollinearity was not a problem. Sampling adequacy for factor analysis (FA) was tested using high values of Keriser - Meyer - Olkin (KMO) statistic of greater than 0.5 and confirmed by Bartlett's test of sphericity significant at $p \leq 0.05$ [53]. Principal Component Analysis (PCA) was conducted for all items with varimax rotation to yield a KMO of 0.809 with Bartlett's test of sphericity being significant, $p=0.000$. It was therefore deduced that the data sample was adequate for FA. Hosmer and Lemeshow (H-L) was used to test Goodness of fit for the model [54]. Since the $\mathrm{H}-\mathrm{L}$ test had a chi square 6.678 and $p$ value of 0.572 , which was greater than $p>0.05$ [49], the model was concluded to be of good fit and adequately fitted the data.

\subsection{Data Analysis}

Descriptive statistics were used to meaningfully describe distribution and determine variables' significance. Inferential statistics were used to establish the relationship between HRPs and retirement preparedness and included FA, correlation, binary logit regression (LR) [55]. Logit regression established the relationships between the variables and tested the hypotheses, to determine the likelihood of teachers' ReP. Therefore, the study tested the effect of HRPs variables on teachers' ReP. The dependent variable was expected to be either the teachers were prepared for retirement coded as one (1), otherwise zero (0). In testing hypotheses $(\mathrm{H})$, the likelihood ratio statistic was used. The outcome was interpreted as statistically significant if ( $p \leq$ 0.05 ) and hence reject $\mathrm{H}_{0}$. The logit models were okay if $p \leq$ 0.05 . Further interpretation was done in terms of odds ratio which were obtained by taking the antilog of the slope coefficients to reveal the number of times the regress is influenced by the regressor [56]. The logit model is indicated in models 1 and 2.

$$
\begin{gathered}
\operatorname{Logit}[p]=\ln \{p / 1-p\}=\beta_{0}+\beta_{1} X_{1}+\mathrm{u}_{\mathrm{i}} \\
\operatorname{Logit}[\mathrm{p}]=\beta_{0}+\beta_{1} \mathrm{FWA}_{1}+\beta_{2} \mathrm{FAN}_{2}+\beta_{3} \mathrm{EDP}_{3}+\beta_{4} \mathrm{CD}_{4}+\mathrm{u}_{\mathrm{i}}
\end{gathered}
$$

Where;

Logit [p] is the probability of the teachers' preparedness

$\mathrm{B}_{0}$ is the Constant

$\beta_{1}$ to $\beta_{4}$ are the Beta coefficients from the logs of the odds ratio function

$\mathrm{FWA}_{1}$ is Flexible Work Arrangements

$\mathrm{FAN}_{2}$ is Formation of Alumni Network

$\mathrm{EDP}_{3}$ is Employee Disengagement Process

$\mathrm{CD}_{4}$ is Career Development

$\mathrm{u}_{\mathrm{i}}$ is error term or random variables

\section{Research Findings}

\subsection{Respondents Characteristics}

The demographic characteristics of respondents was gender, highest level of education, year of birth and number of years worked under TSC (Table 1). The study had response rate of $90 \%$, which was very good [56]. The 37 items had very good reliability with Cronbach's alpha $(\alpha)$ 0.853 .

Table 1. Characteristics of Respondents.

\begin{tabular}{llll}
\hline Variable & & Frequency & Percentage \\
\hline \multirow{3}{*}{ Gender } & Male & 174 & 57.6 \\
& Female & 128 & 42.4 \\
& Total & 302 & 100 \\
& Diploma & 67 & 22.1 \\
Highest level of & Degree & 172 & 57.0 \\
education & Postgraduate Diploma & 34 & 11.3 \\
& Masters & 29 & 9.6 \\
& Total & 302 & 100 \\
& $1956-1960$ & 60 & 19.8 \\
Year of Birth & $1961-1965$ & 167 & 55.4 \\
& After 1965 & 75 & 24.8 \\
& 1967 & 46 & 15.2 \\
Length of service & Total & 302 & 100 \\
under TSC (years) & $10-15$ & 1 & 0.3 \\
& $16-20$ & 9 & 3.0 \\
& $21-25$ & 68 & 22.5 \\
& $26-30$ & 171 & 56.6 \\
& Over 30 & 53 & 17.6 \\
& Total & 302 & 100 \\
\hline
\end{tabular}

Male teacher respondents were the majority $(57.6 \%, 174)$. Most of the pre-retiree teachers had either first degree $(57.0 \%, 172)$ or diploma $(22.2 \%, 67)$ as the highest level of education. The longest service offered by the pre-retirees was 39 years and the least 10 years giving a range of 29 , mean 
score of 27.72 with a standard deviation of 3.66. years. Majority of the pre-retirees had 26 to 30 years of service.

\subsection{Variables Characteristics}

The four variables of HRPs enabled the respondents to provide opinions on how well their employer organization directly or indirectly manifested practices that made the preretirees prepared for retirement. The variables characteristics are presented in Table 2.

Table 2. Characteristics of Variables.

\begin{tabular}{lllll}
\hline Variable & No. of Items & Cronbach's Alpha & Mean & S. Dev. \\
\hline Flexible Work Arrangements & 9 & 0.804 & 1.60 & 1.92 \\
Formation of Alumni Networks & 5 & 0.757 & 2.33 & 1.00 \\
Employee Disengagement Process & 19 & 0.703 & 2.90 & 1.17 \\
Career Development & 24 & 0.812 & 2.19 & 1.24 \\
Overall Human Resource Practices & 37 & 0.869 & 2.16 & 1.30 \\
Retirement preparedness & 10 & 0.809 & 1.18 \\
\hline
\end{tabular}

The study adopted $\alpha \geq 0.7$ as threshold of good reliability [56]. Table 2 shows overall HRPs had very good reliability ( $\alpha$ $\geq 0.869$ ) with a mean score of 2.19 and standard deviation of 1.18. The aggregate mean score for FWA was 1.6 and standard deviation of 1.02. It was thus the opinion of most respondents that FWA were not in existence. This is evidenced by each of the nine items having a mean score of less than 2.0. The standard deviations were generally low, implying the employer organization had not put in place FWAs for the pre-retiree teachers. The study findings suggest that pre-retiree teachers are expected to be in school from morning till evening, and sometimes during weekend. Teachers neither made personal arrangements in the teaching timetable nor left school when without a lesson. In addition, teaching timetables lacked special considerations even for lactating mothers. Pre-retiree teachers neither had options of working few hours to receive pay on pro-rata (part time basis) nor working by splitting full-time job between two or more part-time teachers (job sharing basis). The findings also revealed there were very slim existing opportunities for retired teachers to work on contract or casual/temporary basis.

The aggregate mean score for FAN was 1.92 and standard deviation of 1.17 . The respondents expressed that alumni networks were in existence to a small extent. The five items had a mean score of between 1.53 and 2.30 hence interpreted that the FAN was rare. Some respondents were of the opinion that employer was not concerned about retired teachers $(\mathrm{M}=$ 2.40; SD 1.51). Besides, the respondents reported lack of social forums for retired teachers organized by the employer $(\mathrm{M}=1.82$; SD 1.16). Moreover, respondents $(\mathrm{M}=1.53$; SD $=0.91)$ and $(\mathrm{M}=1.56 ; \mathrm{SD}=0.95)$ acknowledged absence of support services (such as social clubs) funded by employer for retirees and for pre-retiree teachers. This finding avail an impression that neither the pre-retirees nor the retired teachers had formed alumni networks.

For EDP, the aggregate mean score was 2.33 and standard deviation of 1.24. This implies that EDP was in existence to a small extent. However, the large standard deviation indicates a wide variation in the opinions of the respondents. The great disparity in respondents' opinions is demonstrated by the range of mean score for the 19 items that ranged from 1.35 to 4.73. Two items were outliers and rated very highly; namely, retirement date in the monthly pay slip $(M=4.73 ; \mathrm{SD}=$ 0.76 ), and awareness of retirement benefits are based on direct Benefit $(\mathrm{DB})$ pension plans $(\mathrm{M}=3.71$; $\mathrm{SD}=1.42)$. Otherwise, the range was from mean score of 1.35 to 2.84 . Sensitization of pre-retiree teachers by employer about engagement in alternative activities during retirement life and community emersion were in the level of small extent $(\mathrm{M}=$ 2.46; $\mathrm{SD}=1.41)$ and $(\mathrm{M}=1.94 ; \mathrm{SD} 1.23)$ respectively. It was the opinion of $82.1 \%$ (248) respondents that sensitization of teachers about retirement planning immediately after appointment as teachers was non-existent $(\mathrm{M}=1.35$; $\mathrm{SD}=$ 0.87). The finding suggests that employer the organization was not doing well in creating an enabling environment for ESP. This implies that, in spite of the employer informing teachers about the mandatory retirement date on the pay slip, little was done to assist the pre-retiree teachers to plan for retirement life.

The last sub variable, $\mathrm{CD}$, had an aggregate mean score of 2.90 and standard deviation of 1.30 , indicating that $\mathrm{CD}$ was in existence to the level of moderate extent. The large standard deviation, however, suggest presence of a wide variation in respondents' opinions. The 4 items had mean score ranging from 1.90 to 3.66 . The findings therefore indicate pre-retiree teachers were moderately clear of their next career path, and knew what to do to earn a living as retirees $(\mathrm{M}=3.66$; $\mathrm{SD}=1.17)$. Similarly, the pre-retirees indicated having knowledge of opportunities available to them upon retirement $(\mathrm{M}=3.20 ; \mathrm{SD}=1.36)$ and expressed confidence of having planned for career options in retirement $(\mathrm{M}=2.82 ; \mathrm{SD}=1.43)$.

\section{Discussions and Implications}

The small aggregate mean score for FWA $(\mathrm{M}=1.6$; $\mathrm{SD}=$ 1.02) together with all items having a $\mathrm{M}<2.0$ implies that employer had very little FWAs practices. This is despite Wood, et al. (2010), contending that organizations should establish FWAs such as work scheduling, flexible hours, voluntary work-time reductions, phased retirement [33]. The findings were contrary to those of Pillay (2010) that employees with university education and in professional positions were more likely to prefer gradually phased retirement through part time or casual employment [13]. The 
findings also contradict Cahill, et al. (2013), that organizations allow FWAs such as flexible work schedules, flexible work options, and flexible retirement options as part of HR strategy to support employees transitioning to retirement [35]. The findings denote inherent danger of retirees diving into unfamiliar territories on reaching MRA. Deloitte (2014) posit that, FWAs is not only essential to preretirees but also to all employees, especially generation $\mathrm{Y}$ who fervently prefer flexibility [26]. Nonetheless, the findings concur with Seike, et al. (2012), that most organizations lacked enthusiasm in establishing FWAs [58]. Since FAN was in the level of small extent $(\mathrm{M}=1.92 ; \mathrm{SD}=$ 1.17), with the highest item having $M=2.30$, the findings portray seldom FAN. This unveils deficiency of social forums (such as social clubs) for retirees besides workmates. The findings exhibit an impression that neither the preretirees nor the retired teachers had formed alumni networks. The findings failed to support the observations of Cahill, et al. (2013) that establishment of corporate alumni networks was another important HRP in organizations' retirement preparedness strategy [35]. The infinite danger to the preretirees is suffering from psychosocial consequences such as social exclusion and loss of friendship [2].

The findings for EDP revealed an aggregate mean score in the level of small extent $(\mathrm{M}=2.33 ; \mathrm{SD}=1.24)$. This showed a wide range of respondents' opinions as exhibited by the high standard deviation. The items demonstrated a large difference in respondents' opinions as exposed by the mean score ranging from 1.35 to 4.73 . By pre-retiree indicating that employer failed to organize seminars about retirement $(\mathrm{M}=$ 2.67; SD 1.45), it implies that, monthly reminder about retirement date on the pay slip added no value to pre-retiree teachers in planning for retirement life. This may be attributed to pre-retirees' view of MRA as a forced activity $(\mathrm{M}=2.69$; SD 1.54), with some suggesting it be abolished $(\mathrm{M}=2.84 ; \mathrm{SD}=1.63)$. Conceivably, abolition of MRA is the trend by countries like USA, New Zealand, Australia, Canada and UK [33, 59]. Notably, some pre-retirees expressed unwillingness to continue teaching past MRA even if given a chance. However, there were no policies in place for this considerations $(\mathrm{M}=1.60 ; \mathrm{SD} 1.02)$. The teachers were left to make personal initiative on retirement planning. The findings therefore indicate that the employer had not taken cognizance of the dynamics that surround older employees' processes of workplace disengagement.

As pointed out by Topa et al. (2018) some pre-retirees experience mental withdrawals from their jobs years before they actually retire; yet, others would continue to work during retirement [37]. The respondents expressed dismal level of saving for retirement since they relied on DB pension plans without any voluntary contribution, despite being conscious that retirement benefits were inadequate to maintain their current living standard. The findings are inconsistent with Franzen (2010) that, the trend is for employers to replace DB pension plans with DC pension plans [60]. Worse still, the findings indicate that employees neither knows the retirement benefits to expect nor how pension was calculated upon retirement. The study findings imply that facilitation of pre-retiree teachers' disengagement process by the employer is in indeterminate state despite its great importance. This partly agrees with Wang at al. (2010) that, role of retirement transition reasonably remains ambiguous to both employers and employees [5]. Employers should facilitate EDP because, its deficiency precipitate preretirees to suffer effects of mental withdrawal from their jobs long before actual retirement, a type of mourning due to inadequate ReP making them less productivity [37].

Findings on career development showed an aggregate mean score to the level of moderate extent $(\mathrm{M}=2.90 ; \mathrm{SD}=$ 1.30 ), with a large variation in respondents' responses as demonstrated by range of mean score of items (1.90 to 3.66). The CD findings support those of Donaldson et al. (2010) that, without employers creating opportunities for employees to control conditions in which they exit the work place, transition and adjustment to retirement becomes apprehensive [16]. Indeed, organizations that incorporate life course perspective in $\mathrm{CD}$ of pre-retirees provide positive effects to post retirement life [16]. As theorized by Wang at al. (2010), retirement preparedness includes standard career development processes [5].

Logistic regression was carried out to predict ReP of 302 pre-retiree teachers using indicators of HRPs (FWA, FAN, EDP, and CD) as predictors (Table 2). The researchers envisioned that the four variables informed the effect of HRPs on ReP. The outcomes of the dichotomous logistic regression is exhibited in Table 3.

Table 3. Hypotheses Testing.

\begin{tabular}{llllll}
\hline & $\boldsymbol{\beta}$ & $\mathbf{t}=\boldsymbol{\beta} / \mathbf{S E}$ & Wald & P-Value & Exp (B) \\
\hline Flexible Work Arrangements & .354 & 3.570 & 14.176 & .002 & .711 \\
Formation of Alumni Networks & .268 & 3.892 & 12.521 & .001 & .001 \\
Employee Disengagement Process & .433 & 4.115 & 11.154 & .000 & 3.541 \\
Career Development & .512 & 3.541 & 10.120 & & .000 \\
Observations (n) & & 302 & & \\
Nagelkerke R Square & $(4 \mathrm{df})$ & 0.307 & & \\
Model Chi - square & & 75.562 & & \\
Classification Rate & & 72.8 & & \\
-2 Log likelihood & $(8 \mathrm{df})$ & $309.353^{\mathrm{a}}$ & & \\
Hosmer and Lemeshow Test & 9.921 & & \\
Dependent Variable is Retirement Preparedness & & & & \\
Note $p \leq 0.05$ & & & & \\
\hline
\end{tabular}


Running LR shown in model 2, gave the findings as presented in Table 3. Likelihood ratio chi square of 75.562 with a $p=0.000$ shows the model was significant. The Nagelkerke R Squared (0.307) implies that the model variables explained $30.7 \%$ of the variation in $\mathrm{ReP}$ which is a remarkable relationship between HRPs and ReP. The -2 Log likelihood of 309.353 point out that the model fitted the research data. The percentage correctly predicting that event occurred (prediction sensitivity) was 1196/201 which translated to $97.5 \%$, while that of the event not occuring was $77 / 101$ translating to $23.8 \%$. The prediction had an overall success rate of $72.8 \%$. The four predictor variables had positive $\beta$ coefficients of .354, .268, .433 and .512 for FWA, FAN, EDP and CD respectively, indicating that their increase is associated with increased log odds of ReP.

The odds ratio of FWA (expressed by Exp (B)) was 1.711 implying that, a unit increase in FWA increases the likelihood of ReP by pre-retiree teachers by $71.1 \%$. From these findings therefore, FWA was statistically significant in predicting preretiree teachers' retirement preparedness. The researchers thus found a significant positive relationship between FWA and ReP of pre-retiree teachers. Thus, the first hypothesis was supported and the study accepted $\mathrm{H}_{1}$ that, there is a significant effect of FWA on ReP among public secondary school teachers in Kenya since $\beta \neq 0$ and $p$ - value was significant $(p=0.002)$. The authors concluded that, there exists a significant positive relationship between FWA and $\mathrm{ReP}$ of pre-retiree teachers of public secondary schools in Kenya.

The odds ratio of FAN was 5.541; meaning, a unit increase in FAN increases the likelihood of ReP by pre-retiree teachers by $54.1 \%$. From the results, FAN was statistically significant in predicting pre-retiree teachers' retirement preparedness. The study therefore established a significant positive relationship between FAN and ReP of pre-retiree teachers. The second hypothesis was supported and the study accepted $\mathrm{H}_{2}$ that, there is a significant effect of FAN on ReP among public secondary school teachers in Kenya since $\beta \neq 0$ and $p=0.001$, hence significant. The study concluded that, there exists a significant positive relationship between FAN and ReP of pre-retiree teachers of public secondary schools in Kenya.

The odds ratio of the third variable, EDP was 3.686. This means that a unit increase in EDP increases the likelihood of ReP by pre-retiree teachers by $68.6 \%$. The findings indicate that, EDP was statistically significant in predicting pre-retiree teacher's retirement preparedness. The study found a significant positive relationship between EDP and ReP of pre-retiree teachers. The third hypothesis was thus supported and the study accepted $\mathrm{H}_{3}$ that, there is a significant effect of EDP on ReP among public secondary school teachers in Kenya since $\beta \neq 0$ and $p=0.001$, hence significant. The study concluded that, there exists a significant positive relationship between EDP and $\mathrm{ReP}$ of pre-retiree teachers of public secondary schools in Kenya.

The fourth variable was CD and had odds ratio of 2.497.
This implied that a unit increase in $\mathrm{CD}$ increases the likelihood of ReP by pre-retiree teachers by $49.7 \%$. The study results show that, CD was statistically significant in predicting pre-retiree teacher's retirement preparedness. The study therefore established a significant positive relationship between $\mathrm{CD}$ and ReP of pre-retiree teachers. The forth hypothesis was consequently supported and the study accepted $\mathrm{H}_{4}$ that, there is a significant effect of CD on ReP among public secondary school teachers in Kenya since $\beta \neq 0$ and $p=0.000$, thus significant. The study concluded that, there exists a significant positive relationship between EDP and ReP of pre-retiree teachers of public secondary schools in Kenya.

Hypotheses findings support empirical findings of previous studies that organizations had essential roles in providing a conducive environment that supports employee retirement planning and $\mathrm{ReP}$ by developing and implementing appropriate HRPs $[16,18]$. There is therefore need for organizations to manage the mix of swelling number of older and younger workers in the work place through development of relevant HRPs [61]. Certainly, the empirical findings that HRPs had a significant positive effect on ReP is pertinent in facilitating ESP from employer organization to post retirement life because HRPs provide an enabling environment for individuals to prepare for retirement. The HRPs should therefore include FWA, FAN, EDP and CD. These findings on HRPs paints a gloomy picture of preretiree teachers getting into retirement that neither the employer nor themselves planned for in advance. The study therefore establishes that the employer is devoid of HRPs that reflect ReP for pre-retiree teachers.

The HRPs provide knowledge that reinforce CT, LCP and the TPB as theories used in retirement $[18,16]$. The study therefore contributes to the body of knowledge by increasing comprehension of the theoretical underpinnings in the study of ESP for ReP. in addition, the findings deliver empirical evidence on the role of HRPs in HRM on retirement planning for ReP. Consequently, the study extends the frontier of knowledge by providing empirical evidence of variables significant in ESP. The findings of this study have implications to government, policy makers and practitioners to induce employer organizations to promote policies and practices that would increase likelihood of pre-retirees ReP through advertent development and implementation of HRPs as a HR strategy for ESP. The Kenyan government would better empower the employees by enforcing employers to appropriate HRPs that foster ReP as enablers of senior citizens to age gracefully without relying on financial donations for upkeep.

\section{Conclusions}

From the research findings and the hypotheses testing results, the study concludes that the HRPs have a significant positive effect on ReP in the life of pre-retiree teachers in public secondary schools. FWA, EDP, FAN and CD (in that 
order of ranking) are imperative in strengthening postulations by CT, LCP and the TPB that life should continue without major disturbances. However, the study found that employer organizations lack sufficient HRPs to empower strategic planning for ReP by the workforce. The study proposes employer organizations to put in place necessary mechanisms to develop and implement appropriate HRPs that will assist employees to prepare for imminent retirement. This conclusion is very vital because it boldly raises a discourse to researchers and other players on HRPs geared towards the wellbeing of the most important resource - the people - for the sake of their postemployment life which is currently abandoned.

\section{Limitations and Recommendations for Further Study}

Some aspects may limit the extent of generalization and applicability of the findings. The study depended on subjective data, self-reported in the questionnaires (survey) by pre-retiree teachers (triangulated by interview) which may have resulted to over or under reporting on the level HRPs. The respondents were only pre-retirees (beneficiaries of HRPs). Perhaps it would have been fair to hear from employer organization representatives. The study also applied only four variables to comprise HRPs which may have not been exhaustive. Finally, the study was conducted only in public secondary schools in Kirinyaga and Murang'a Counties. Secondary school teachers being a profession with strict code of service, to a small extent limits the level of generalizations. Further research may be conducted to address some or all of the cited limitations and enlarge the methodology by employing longitudinal studies and other methods of data collection.

\section{References}

[1] Olufemi, O. O. \& Fachiku, C. O. (2015). Workers Knowledge of Prospects and Challenges awaiting retirees at Retirement in Nigeria. Asia Pacific Journal of Education, Arts and Sciences, $2(1), 44-52$.

[2] Gathiira, T. G., Muathe S. M. \& Kilika, J. M. (2019). Psychosocial Programmes and Employees Retirement Preparedness: Empirical Evidence from the Educational Sector in Kenya. International Journal of Business Administration, 10 (2), 82-95.

[3] Petkoska, J., \& Earl, J. K. (2009). Understanding the influence of demographic and psychological variables on retirement planning. Psychology and Aging, 24, 245-251.

[4] Lusardi, A., \& Mitchell, O. (2011). How ordinary consumers make complex economic decisions: Financial literacy and retirement readiness, NBER Working Paper, 15350.

[5] Wang, M. \& Shultz, K. S. (2010). Employee retirement: a review and recommendations for future investigation. Journal of Management, 36 (1), 172-206.
[6] McVittie, C., \& Goodall, K. (2012). The ever-changing meanings of retirement. American Psychologist. 67 (1), pp $75-76$.

[7] Shultz, K. S. \& Henkens, K. (2010). "Introduction to the changing nature of retirement: an international perspective", International Journal of Manpower, 31 (3), pp. 265 - 270.

[8] Adams, G. A., \& Rau, B. L. (2011). Putting Off Tomorrow to Do What You Want Today. American Psychologist, 66 (3), 180-192.

[9] Nicolaisen, M., Thorsen, K., Eriksen, S. H. (2012). Jump into the void? Factors related to a preferred retirement age: gender, social interests, and leisure activities. International Journal Aging and Human Development, 75 (3), pp 239271.

[10] Barnett, I., van Sluijs, E. M., \& Ogilvie, D. (2012). Physical activity and transitioning to retirement: A systematic review. American Journal of Preventive Medicine, 43, 329-336.

[11] Jenkins, E. D. A. (2013). "The work-to-retirement transition of academic staff: attitudes and experiences". Employee Relations. 35 (3), $322-338$.

[12] Sargent, L. D., Lee, M. D., Martin, B \& Zikic, J. (2012). Reinventing retirement: New pathways, new arrangements, new meanings. Human relations, 66 (1), 3-21

[13] Pillay, H., Kelly, K., \& Tones, M. (2010). "Transitional employment aspirations for bridging retirement", Journal of European Industrial Training, 34 (1), pp. 70 - 86.

[14] World Health Organization. (2012). World Health Statistics. Geneva, Switzerland: Author.

[15] Mariappanadar, S. (2012). Do retirement anxieties determine bridge employment preference? A study among pre-retirees in the Australian construction industry. Emerald Group Publishing Limited, 42 (2), pp 176-204.

[16] Donaldson, T., Earl, J. K. \& Muratore, A. M. (2010). Extending the integrated model of retirement adjustment: Incorporating mastery and retirement planning retrieval. Journal of Vocational Behaviour, 77, 279-289.

[17] Armstrong, M. \& Taylor, S. (2014). Amstrong's Handbook of Human Resource Management Practice. 13th Ed. London: Kogan Page.

[18] Wohrmann, A. M., Deller, J. \& Wang, M. (2014). Postretirement Career Planning: Testing a Model Based on Social Cognitive Career Theory. Journal of Career Development, 41 (5), 363-381.

[19] Deller, J., Liedtke, P. M., \& Maxin, L. (2009). Old-age security and silver workers: An empirical survey identifies challenges for companies, insurers and society. Geneva Papers on Risk and Insurance - Issues and Practice, 34, 137-157. doi: 10.1057/gpp.2008.44.

[20] Wang, M., Henkens, K. \& Van Solinge, H. (2011). Retirement Adjustment: A Review of Theoretical and Empirical Advancements. American Psychologist. Advance online publication.

[21] Ajzen, I. (1991). Organizational Behaviour and Human Decision Processes. University of Massachusetts, 50, 179211. 
[22] Davis, M. A. (2003). Factors related to bridge employment participation among private sector early retirees. Journal of Vocational Behaviour, 63, 55-71.

[23] Sheppard, B. H., Hartwick, J. \& Warshaw, P. R. (1988). The theory of reasoned action: A meta-analysis of past research with recommendations for modifications and future research. Journal of Consumer Research, 15, 325-34.

[24] Van Dalen, H. P. Henkens, K., Henderikse, W., \& Schippers, J. (2010). Do European employers support later retirement?", International Journal of Manpower, 31 (3), pp. 360 - 373.

[25] Ozgen, M., Tuzlukaya, S. E., \& Cigdemoglu, C. (2020). A phenomenological study of military retirees: Reasons for retirement and post-retirement employment in Turkish military. Journal of Research in Emerging Markets, 2 (1), pp. 62-78, doi: $10.30585 /$ jrems.v2i1.421

[26] Deloitte. (2014). Big demands and high expectations. The Deloitte Millennial survey, January, 2014, http://www2.deloitte.com/content/dam/Deloitte/global/Docum ents/About-Deloitte/gx-dttl-2014-millennial-surveyreport.pdf.

[27] Benko, C., Erickson, R., Hagel, J., \& Wong, J. (2014). Beyond Retention: Building passion and purpose, Deloitte Consulting LLP.

[28] Casey, R., \& Berger, E. (2015) "Enriching or Discouraging? Competing Pictures of Aging and Paid Work in Later Life," Population Change and Life course Strategic Knowledge Cluster Discussion Paper Series 3 (3). Available at: http://ir.lib.uwo.ca/pclc/vol3/iss3/3

[29] Appannah, A., \& Biggs, S. (2015). Age-friendly organizations: The role of organizational culture and the participation of older workers. Journal of Social work, 29 (1), 37-51

[30] Bal, P., De Jong, S. B., Jansen, P. W., \& Bakker, A. B. (2012). Motivating employees to work beyond retirement: A multilevel study of the role of Ideals and unit climate. Journal of Management Studies, 49 (2), 306-331.

[31] Tishman, F. M., Van Looy, S., \& Bruyere, S. M. (2012). Employer Strategies for Responding to an Aging Workforce. The National Technical Assistance and Research Center.

[32] Schlosser, F., Zinni, D., \& Armstrong-Stassen, M. (2012). Intention to unretired. Career Development International, 17 (2), 149-167.

[33] Wood, A., Robertson, M., \& Wintersgill, D. (2010). A comparative review of international approaches to mandatory retirement. Department for Work and Pensions, Report No. 674.

[34] Flynn, M. (2010). The United Kingdom government's 'business case' approach to the regulation of retirement. Aging and Society 30 (3), 421-443.

[35] Cahill, K. E., Giandrea, M. D. \& Quinn, J. F. (2013) 'Bridge employment', in M. Wang (ed.), The Oxford Handbook of Retirement, Oxford: Oxford University Press

[36] Quinn, J. F. (2010). Work, retirement, and the encore career: Elders and the future of the American workforce. Generations, $34,45-55$.

[37] Topa G., Depolo, M., \& Alcover., C-M. (2018). Early Retirement: A Meta-analysis of Its Antecedent and Subsequent
Correlates. Front. Psychol, 8 (2151), doi: 10.3389/fpsyg.2017.02157

[38] Henry, H., Zachar, H., \& Desmette, D. (2017). Future time perspective in the work context: A systematic review of qualitative studies. Front. Psycol. 8 (413), doi: 10.3389/fpsyg. 2017.00413.

[39] Potocnik, K., \& Sonnentag, S. (2013). A longitudinal study of wellbeing in older workers and retirees: The role of engaging in different types of activity. Journal of Occupational and Organizational Psychology, 86, 497-521.

[40] Beehr, T. A., \& Bennett, M. M. (2015). Working after retirement: Features of Bridge employment and research directions. Working Age Retirement. 1 (112-128), doi: 10.1093/worker/wau007.

[41] Schreurs, B., van Emmerik, H. V., Decuyper, N., Notelaers,. \& Dewitte, H. (2011). Job demands-resources and early retirement intension: differences between blue and white collar workers. Econ Indus. Democracy. 32, 47-68, doi: $10.1177 / 0143831 X 10365931$.

[42] Neal, S. G. (2015). Factors that influence retired executives in higher education to reenter the workforce (Order No. 10003437). Available from ProQuest Dissertations \& Theses Global.

[43] Ministry of Education (2010). Educational Statistical Booklet 2003-2007, Government Printers, Nairobi, Kenya

[44] NACADA, (2014). Summary Report of Morbidity and Mortality caused by Alcohol Consumption in various parts of the country, Kenya. Author.

[45] Pannor Silver, M., Pang, N. C., \& Williams, S. A. (2015). "Why give up something that works so well?": Retirement expectations among academic physicians. Educational Gerontology, 41 (5), 333-347

[46] Baloch, R. S., Baloch, R. A., Baloch, A. B., \& Yousafzai, S. A. (2019). The influence of psychosocial adjustment factors on team embeddedness at the work place. Int. J. Management and Philosophy. 12 (3), 312-328

[47] Bamberger, P. A. (2014). Winding Down and Boozing Up: The Complex Link Between Retirement and Alcohol Misuse. Work, Aging and Retirement, 00 (00), 1-20.

[48] Sekaran, U., \& Bougie, R. (2009). Research methods for business. (5th Ed.), Wiley Publication.

[49] Chawla, D., \& Sondhi, N. (2011). Research Methodology: Concepts and Cases. New Delhi: Vikas Publishing House Pvt Ltd.

[50] Fox, N., Hunn, A., \& Mathers, N. (2009). Sampling and Sampling Size Calculation. The National Institute for Health Research, Research Design Service, Yorkshire.

[51] Chauvet, G. (2015). Coupling Methods for Multistage Sampling. The Annals of Statistics, Vol. 43, No. 6, 2484-2506.

[52] Field, A. P. (2012). Discovering Statistics using R. New Delhi: Sage Publications

[53] Field, A. P. (2013). Discovering statistics using SPSS. 2nd Edition. London: Sage.

[54] Damodor, N. G. (2009). Basic econometrics. New DelhiIndia: MacGraw-Hill Publishing Co. Ltd. 
[55] Cooper, D. R., \& Schindler, P. S. (2011). Business research methods. (11 ${ }^{\text {th }}$ ed). New Delhi-India: MacGraw-Hill Publishing Co. Ltd.

[56] Saunders, M., Lewis, P., \& Thornhill, A. (2009). Research methods for business students. ( $5^{\text {th }}$ ed.). Great Britain: Prentice Hall.

[57] Zikmund, G. W., Babin, B. J., Carr, C. J. \& Griffin, M. (2010). Business research methods ( $8^{\text {th }}$ Ed.). South-Western: Cengage Learning.

[58] Seike, A., Biggs, S., \& Sargent, L. D. (2012). Organization, adaptation and HR needs for an aging population. Beard J, Biggs S, Bloom D, Fried L, Hogan P, Kalache A and
Olshansky J (Eds.). Global Population Aging: Peril or Promise? Davos, Switzerland: World Economic Forum.

[59] Ebbinghaus, B. (2011). The Varieties of Pension Governance: Pension Privatization in Europe, Oxford: Oxford University Press.

[60] Franzen, D. (2010). Managing Investment Risk in Defined Benefit Pension Funds OECD; Working Papers on Insurance and Private Pensions. No. 38. OECD Publishing.

[61] Heijden, B. I. J. M. V. D., Schalk, R. \& Veldhoven, M. J. P. M. V. (2008). Ageing and careers: European research on longterm career development and early retirement, Career Development International, Vol. 13 No. 2, 85-89. 